\title{
Extraction of Cerium (IV) Using Di-n-butylsulfoxide in Chloroform from Nitric Acid and Determination with Arsenazo (III) as Chromogenic Reagent
}

\author{
Muhammad Haleem Khan*, Khurram Liaqat, Muhammad Hafeez, \\ Srosh Fazil and Muhammad Riaz \\ ${ }^{1}$ Department of Chemistry, University of Azad Jammu \& Kashmir, Muzaffarabad, Pakistan. \\ Received 17 October 2014, revised 12 January 2015, accepted 20 January 2015.
}

\begin{abstract}
A new and advantageous extraction procedure was developed for extraction of cerium (IV) from nitric acid with di- $n$-butylsulfoxide (DBSO) in perchloric acid. The extracted Ce (IV) was determined spectrophotometrically using $0.01 \%$ solution of arsenazo-III in $3 \mathrm{M}$ per-chloric acid. Various parameters such as equilibration time, metal ion concentration, effect of temperature and diverse ions on the extraction of the Ce (IV) were established. U (VI), Th (IV) and Pb (II) interfere whereas only phosphate and fluoride suppress the extraction among anions. The stoichiometric composition of the cerium complex with DBSO was determined by slope analysis and found to be 1:4. The process of extraction was found to be exothermic. Deionized water was the most appropriate solvent for back extraction of cerium. This method is easier and more sensitive than many of the reported procedures.
\end{abstract}

KEYWORDS

Cerium, extraction, DBSO, perchloric acid, arsenazo-II.

\section{Introduction}

Cerium is the most abundant among rare earth metals and is extracted from monazite, allanite and bastnasite minerals. ${ }^{1}$ Very pure cerium is used for the production of nuclear power and as a catalyst in nuclear and automobile industries, as an alloy with chromium; in microwave devices, television sets, lasers besides some important uses in environmental pollution assessment, agronomy and biochemistry. In addition to this, many cerium compounds has been found important for biomedical applications. $^{2}$

Atomic absorption spectroscopy (AAS) and inductively coupled plasma optical emission spectroroscopy (ICP OES) techniques are not promising for direct determination of cerium and a prior separation is required. ${ }^{3-6}$ The extraction chemistry of cerium has been studied and different extractants such as lueco xylene cyanol (FF), N-phenylbenzo-18-crown-6-hydroxamic acid, tri-n-butyl phosphate (TBP), resorcinarene-N-fenil-acetohydroxamic acid, di-(-2-ethylhexyl) 2-ethylhexyl phosphonate (DEHEHP), cyanex 923, 2-ethylhexyl hydrogen 2-ethylhexyl phosphonate, $\mathrm{N}, \mathrm{N}^{\prime}$-Dimethyl-N, $\mathrm{N}^{\prime}$-diphenyl-pyridine-2, 6-dicarboxyamide (DMDPhPDA), tridodecylamine (TDA), 1-[thenoyl-(2)]-3-3-3-trifluoroacetone (HTTA), di (2-ethylhexyl) phosphoric acid (HDEHP) and tricaprylmethyl-ammonium chloride (TCMA) have been used. ${ }^{7-22}$ In addition to this the extraction chemistry of cerium has also been explored with $\mathrm{N}$-n-octylaniline, acetophenone 2,5 dihydroxy, semicarbazone, Variamine blue, 2,4, dihydroxy benzophenoe benzoic hydrazone, 2,6-dibromo-4-chloro carboxyarsenazo, 4-dimethyl amino-azo benzene-arsenic acid, pyrogallol red, dibromo-p-methyl chloro sulphanzo, propionil promazine phosphate, N-P-chlorophenyl- $p$-methoxy hydroxamic acid, tributylphosphine oxide (TBPO), tricaprylmethylammonium chloride, calix [IV]

* To whom correspondence should be addressed: E-mail: mriazm1@yahoo.com resorcinarene acid derivative $\left[\mathrm{C}_{4} \mathrm{RAHA}\right]$, butyl phosphate, 3-phenyl-4-benzoyl-5-isoxazolone (HPBI), bifunctional ionic liquids, octacarboxymethyl-C-methylcalix , organophosphorous extractants, malachite green, arsenazo (III). ${ }^{23-43}$ However, there are certain limitations associated with extraction of cerium such as interference of different ions, co-extraction, emulsion formation, use of high reagent concentrations less sensitivity and expensive back-stripping reagents.

In this communication, we report the extraction of Ce (IV) with DBSO in nitric acid using arsenazo-III as chromogenic reagent. The proposed method is highly suitable as almost quantitative extraction of cerium is possible. Higher amounts of cerium can be stripped back to deionized water thus the process is economically more favourable.

\section{Experimental}

\subsection{Reagents, Solutions and Apparatus}

All chemicals used were of analytical grade. Cerium sulphate stock solution $\left(1000 \mu \mathrm{g} \mathrm{mL}^{-1}\right)$ was prepared in $2 \mathrm{M}$ sulphuric acid. Solutions of arsenazo-III were prepared by dissolving the measured amount of disodium salt of the compound in $\mathrm{HClO}_{4}$. Salting-out agent solution ( 0.01 molar) was prepared by adding $3.75 \mathrm{~g}$ of $\mathrm{Al}(\mathrm{NO})_{3} .9 \mathrm{H}_{2} \mathrm{O}$ in deionized water and further dilutions were made to prepare solutions of required concentrations. Potassium phosphate, potassium fluoride, sodium sulphate, sodium cyanide, sodium chloride and sodium thiosulphate solutions were made by adding $100 \mathrm{mg}$ of each salt in deionized water and making up the total volume to $10 \mathrm{~mL}$. Uranyl nitrate, thorium nitrate, zinc chloride, lead nitrate solutions were made by adding $100 \mathrm{mg}$ of respective salt in deionized water and making up the total volume of $10 \mathrm{~mL}$. 7.5 M nitric acid solution was made by taking $425 \mathrm{~mL}(15.7 \mathrm{M})$ nitric acid and diluting it to 
$1000 \mathrm{~mL}$ with deionized water and further dilutions were made from that. Nitric acid $(0.1 \mathrm{M})$ and ammonium hydroxide $(0.1 \mathrm{M})$ solutions were made by taking $100 \mathrm{~mL}$ of each from $1 \mathrm{M}$ respective stock solutions and making up dilution to $1000 \mathrm{~mL}$ with deionized water. Di- $n$-butylsufoxide solution $(2 \mathrm{M})$ was prepared by dissolving $32.4 \mathrm{~g}$ of it in chloroform and making the total volume $100 \mathrm{~mL}$. Spectral measurements were obtained using digital spectrophotometer (Shimadzu Japan, model-1601) with an automatic recording device.

\subsection{General Extraction Procedure}

Known amount of the cerium sulphate solution was taken in a $100 \mathrm{~mL}$ glass beaker and was heated (to near dryness) on an electric hot plate. On cooling, $3.0 \mathrm{~mL}$ of the $3.0 \mathrm{M} \mathrm{HNO}_{3}$ was added to it; $2.0 \mathrm{~mL}$ of this solution was pipetted out in a screw-capped (18 $\times 125 \mathrm{~mm}$ ) culture tube and the remaining $1.0 \mathrm{~mL}$ in the $50.0 \mathrm{~mL}$ beaker was treated as reference. The aqueous phase was equilibrated with an equal volume of 1.0 M DBSO in chloroform for $5 \mathrm{~min}$ and phase separation was achieved with centrifugation. One $\mathrm{mL}$ of aqueous solution was pipetted out in another beaker and was heated to near dryness. $3.0 \mathrm{~mL}$ of the arsenazo-III $(0.01 \%)$ in $3.0 \mathrm{M} \mathrm{HClO}_{4}$ was added on cooling and was mixed thoroughly for colour development. The reagent blank was prepared under identical conditions but without metal ions. The absorbance measurement was made at $658 \mathrm{~nm}$ against the reagent blank (Fig. 1). The peak 1 shows the complex. (All presented data are an average of triplicate measurements.)

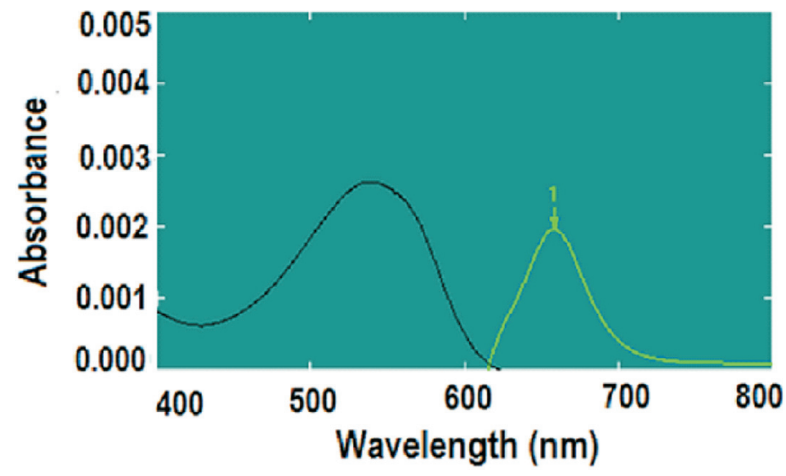

Figure 1 Absorption spectra of Ce complex.

The distribution ratio $(\mathrm{kd})$ was calculated with the following equation:

$$
\mathrm{Kd}=(\mathrm{Ct}-\mathrm{Cex}) / \mathrm{Cex}
$$

In this equation, $\mathrm{Ct}$ and $\mathrm{Cex}$ indicate the total concentration of the cerium in aqueous phase before and after extraction, respectively.

$$
\% \text { extraction }=\mathrm{Kd} \times 100 /(\mathrm{Kd}+1)
$$

Accuracy of the extraction method under study has been explored by extracting cerium contents $\left(1000-5000 \mu \mathrm{g} \mathrm{mL} \mathrm{m}^{-1}\right)$ from Ce (IV) standard solution (Table 1). A significant decrease in

Table 1 Accuracy of the developed procedure.*

\begin{tabular}{ccc}
\hline Ce added $/ \mu \mathrm{g} \mathrm{mL}^{-1}$ & Ce found $/ \mu \mathrm{g} \mathrm{mL}^{-1}$ & \pm Deviation/percentage \\
\hline 100 & 65 & -35 \\
1000 & 960 & -4.0 \\
2000 & 1978 & -1.1 \\
3000 & 2988 & -0.4 \\
5000 & 4990 & -0.2 \\
\hline
\end{tabular}

* Data the average of three measurements. percentage deviation was observed while increasing cerium concentration. It was noted that loading capacity of DBSO for cerium is quite high to extract the metal ions present in the concentration range studied but decrease in percentage deviation of cerium at its high concentration was probably due to fluctuations caused by the dilution at spectrophotometric step. Another possible reason for the decreasing percentage deviation might be the higher metal ion concentration as nitric acid competition for extractant decreases and maximum extraction of cerium occurs which resulted an increase in the expected error. Therefore, we noted that in this extraction procedure, lower concentration of metal ions gives better results.

\section{Results and Discussion}

\subsection{Effect of Nitric Acid Concentration}

Dependency of percentage extraction of cerium with different concentrations of nitric acid (using 1.0 M DBSO in chloroform) was studied (5 min shaking time). Equal volume $(2.0 \mathrm{~mL}$ of each) of organic and aqueous phases was equilibrated. An abrupt increase in the percentage extraction of cerium with increasing concentration of nitric acid reaching a maximum value (76\% for $3.0 \mathrm{M} \mathrm{HNO}_{3}$ ) was observed (Fig. 2). Further increase of the nitric acid concentration caused a decrease in the percentage extraction of cerium in the range of 0.5 to $7.5 \mathrm{M}$. At lower acid strength, percentage extraction was higher due to mild competition between cerium and acid for complexation with DBSO. This might be due to the fact that increasing acid concentration decreases free DBSO concentration thus leading to a stronger competition between metal (cerium) and acid $\left(\mathrm{HNO}_{3}\right)$ for complexation with the extractant. Coordination of DBSO with $\mathrm{HNO}_{3}$ results into (nDBSO. $\mathrm{HHNO}_{3}$ ) adduct. Thus after reaching a maximum (with $3 \mathrm{M}$ nitric acid), percentage extraction decreases with increasing acid concentration.

\subsection{Effect of Equilibration Period}

The shaking time duration affects the extraction of cerium (IV) using 1.0 M DBSO and has been studied while keeping all the parameters constant under previously optimized experimental conditions (Fig. 3). The results are indicative of a sharp enhancement in percentage extraction by increasing shaking period (for $5 \mathrm{~min}$ ) and then a decrease with increasing shaking time. This can be explained on the basis of the fact that equilibration between cerium and DBSO in this system reaches equilibrium saturation with a high rate constant that no further increase in extraction was observed (after 5 min shaking time). Therefore, it appears that equilibrium for $\mathrm{Ce}\left(\mathrm{NO}_{3}\right)_{4} \cdot \mathrm{nDBSO}$ is faster than that of $\mathrm{Ce}\left(\mathrm{NO}_{3}\right)_{4} \cdot \mathrm{nDBSO} \cdot \mathrm{mHNO}_{3}$. After $5 \mathrm{~min}$ more of the latter forms, resulting in less efficient extraction of the metal. In conclusion, disparity of shaking time indicated that a single extraction with DBSO $(1.0 \mathrm{M})$ in chloroform for a maximum of 5 minfrom $\mathrm{HNO}_{3}(3.0 \mathrm{M})$ solution is appropriate for cerium extraction (up to $75 \%$ ). The concentration range of Ce was $10.77 \times 10^{-3}$ to $3.56 \times 10^{-3} \mathrm{~mol} \mathrm{dm}^{-3}$.

\subsection{Effect of Extractant Concentration}

The impact of extractant concentration was explored by changing the concentration from 0.3 to $2.0 \mathrm{M}$ DBSO using chloroform as diluent. All other parameters were kept constant under previously optimized experimental conditions. A curve was constructed between different molarities of DBSO solution versus extraction of cerium (Fig. 4). Maximum percentage extraction was with $1.0 \mathrm{MDBSO}$ and then a decrease was noted. Two factors are potentially responsible for the decrease in the 


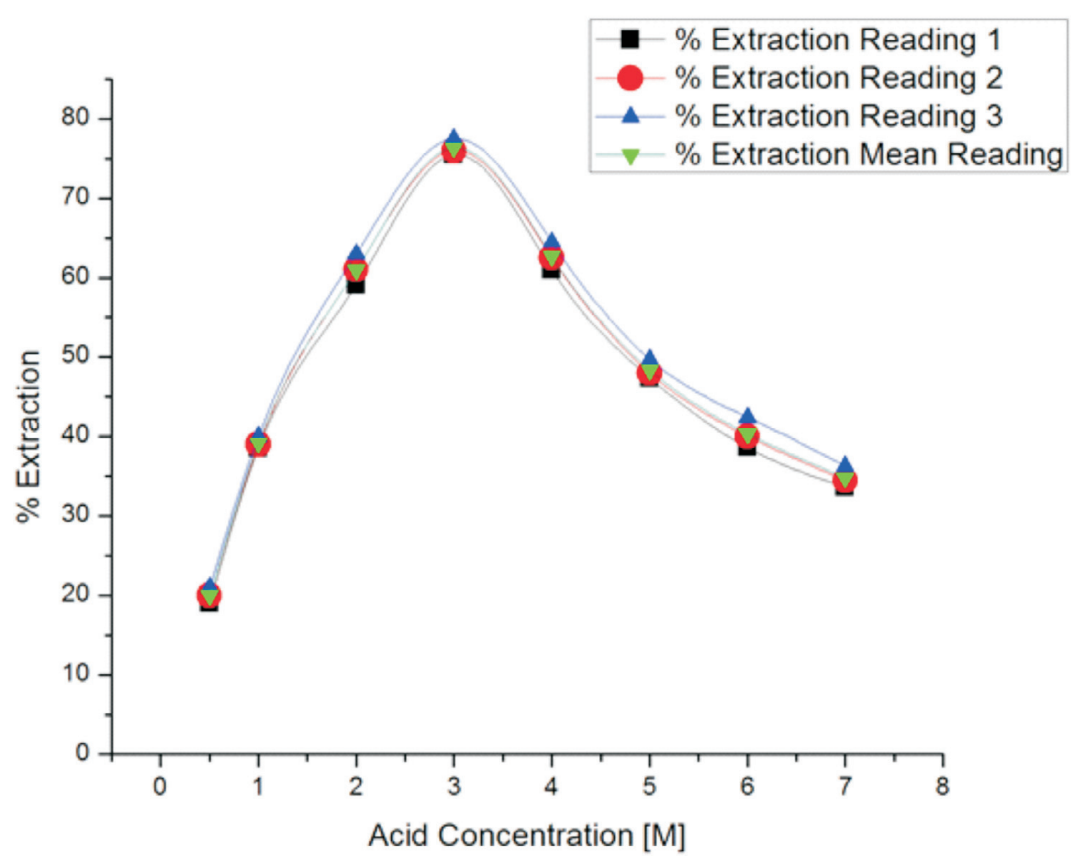

Figure 2 Effect of nitric acid (3.0 M) concentration on the extraction of Ce in the presence of DBSO $(1.0 \mathrm{M}),(\mathrm{n}=3)$.

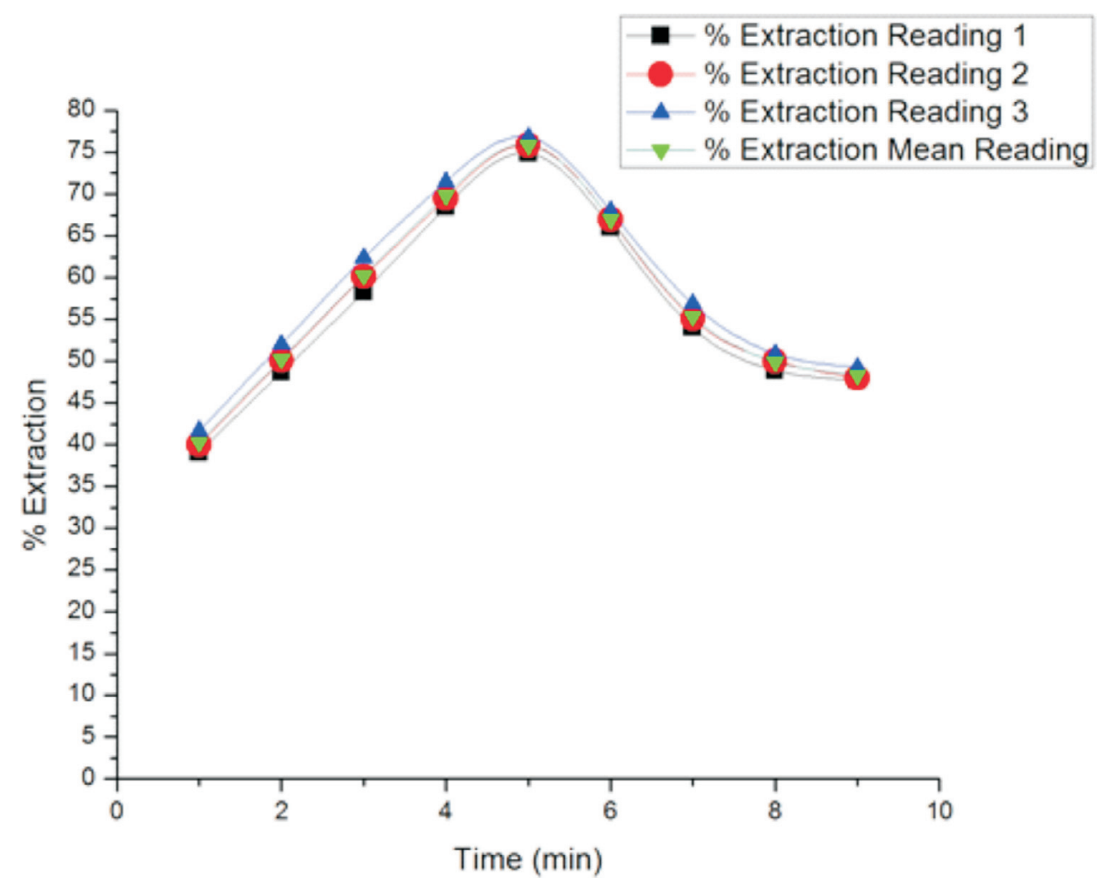

Figure 3 Effect of shaking time on the extraction of Ce (0.1 M DBSO in chloroform and $\left.3.0 \mathrm{M} \mathrm{HNO}_{3}\right),(\mathrm{n}=3)$.

percentage extraction of cerium (with increased concentration of extractant). Firstly, due to extraction of more nitric acid by higher concentration of DBSO solution, aqueous acid concentration decreases resulting into a lower $K_{d}$ value of cerium. Secondly, the volume of the organic phase increases due to more extraction of acid by higher DBSO concentration thus decreasing cerium concentration in the organic phase. Therefore, $1.0 \mathrm{M}$ DBSO (solution in chloroform) was selected as maximum concentration of the extractant for quantitative cerium (IV) extraction. The concentration range of Ce was $10.77 \times 10^{-3}$ to $3.56 \times$ $10^{-3} \mathrm{~mol} \mathrm{dm}^{-3}$.

\subsection{Effect of Metal Ion Concentration}

The extraction potential of DBSO ( 0.2 to $2 \mathrm{M}$ solution in chloroform) from 3.0 $\mathrm{M} \mathrm{HNO}_{3}$ solution for varying concentration

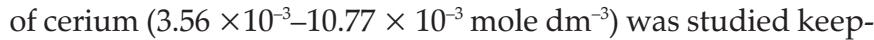
ing other parameters constant (Table 2). These results indicate a quantitative extraction of cerium (IV) for concentration range studied. Percentage extraction increases with increasing DBSO concentration thus indicating the high loading capacity, which is very encouraging for the proposed extraction method.

Since DBSO makes coordinate covalent bonds with $\mathrm{Ce}\left(\mathrm{NO}_{3}\right)_{4}$ it is therefore to vary the concentration to fully understand its role in the extraction process.

\subsection{Effect of a Salting-out Agent}

Varying concentrations of aluminum nitrate $\mathrm{Al}\left(\mathrm{NO}_{3}\right)_{3} \cdot 9 \mathrm{H}_{2} \mathrm{O}$ were used during extraction of cerium keeping other parameters constant (Table 3). On adding nitrate (from aluminum nitrate), the extraction efficiency was increased probably due to partici- 


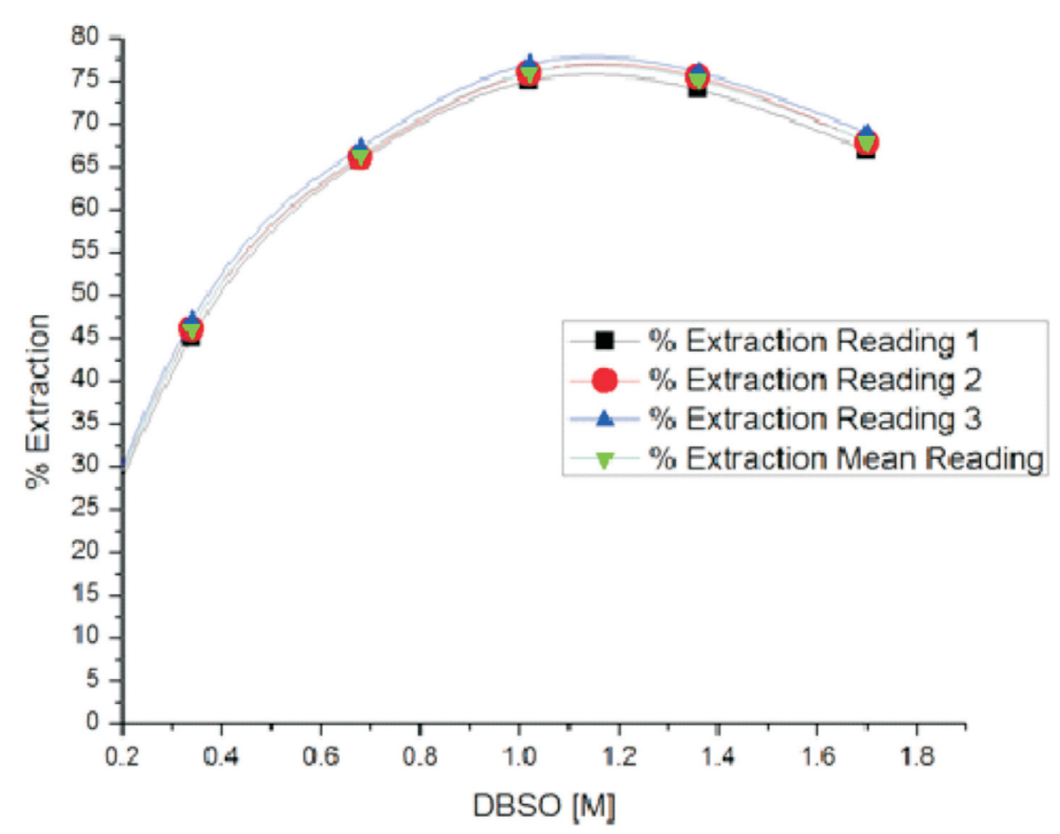

Figure 4 Effect of DBSO (in chloroform) and 3.0 $\mathrm{M} \mathrm{HNO}_{3}$ concentration on extraction of $\mathrm{Ce}$, $(\mathrm{n}=3)$.

Table 2 Effect on of concentration on Ce extraction (1 M DBSO in chloroform and $3 \mathrm{M}$ nitric acid), $(n=3)$.

\begin{tabular}{lcc}
\hline$[\mathrm{Ce}] / \mathrm{mol} \mathrm{dm}^{-3}$ & $\mathrm{DBSO} / \mathrm{mol} \mathrm{d}^{-3}$ & Extraction/percentage \\
\hline $3.56 \times 10^{-3}$ & 0.1 & 55.0 \\
$4.28 \times 10^{-3}$ & 0.2 & 61.5 \\
$4.99 \times 10^{-3}$ & 0.3 & 66.0 \\
$5.70 \times 10^{-3}$ & 0.4 & 71.8 \\
$6.42 \times 10^{-3}$ & 0.6 & 75.0 \\
$7.13 \times 10^{-3}$ & 0.8 & 75.8 \\
$7.85 \times 10^{-3}$ & 1.0 & 77.2 \\
$8.56 \times 10^{-3}$ & 1.0 & 78.9 \\
$9.27 \times 10^{-3}$ & 1.1 & 77.0 \\
$9.99 \times 10^{-3}$ & 1.1 & 76.5 \\
$10.77 \times 10^{-3}$ & 1.2 & 75.4 \\
\hline
\end{tabular}

* Data the average of three measurements.

pation in the metal solvation process. However, with low acid concentration, the nitrates increase extraction by common ion and salting-out effects.

\subsection{Effect of Anions}

The effect of various anions such as $\mathrm{PO}_{4}^{-3}, \mathrm{~F}^{-}, \mathrm{SO}_{4}^{-2}, \mathrm{CN}^{-}, \mathrm{Cl}^{-}$ and $\mathrm{S}_{2} \mathrm{O}_{3}^{-2}$ on the extraction of cerium was studied by mixing the sodium or potassium salts (Table 4). Anions such as $\mathrm{PO}_{4}^{-3}$ and Fhave reduced the percentage extraction while sulphate, cyanide,

Table 3 Salting-out agent effect on Ce extraction (1 M DBSO, 3 M nitric acid, $10.77 \times 10^{-3}$ to $3.56 \times 10^{-3} \mathrm{~mol} \mathrm{dm}^{-3}$ cerium).

\begin{tabular}{cc}
\hline Salting-out agent/mg $3 \mathrm{~mL}^{-1}$ & Extraction/\% \\
\hline Nil & 75.0 \\
50 & 75.1 \\
70 & 75.3 \\
100 & 75.9 \\
150 & 76.4 \\
200 & 77.4 \\
250 & 77.4 \\
\hline
\end{tabular}

* Data the average of three measurements.
Table 4 Anions effect on Ce extraction (1MDBSO, 3 M nitric acid, $10.77 \times$ $10^{-3}$ to $3.56 \times 0^{-3} \mathrm{~mol} \mathrm{dm}^{-3}$ cerium).

\begin{tabular}{lcc}
\hline Anions added $/ 10 \mathrm{mg} \mathrm{mL}^{-1}$ & Extraction/\% & $\begin{array}{c} \pm \text { Deviation (from } \\
\text { normal value) }\end{array}$ \\
\hline Nil & 75.0 & Nil \\
Phosphate & 25.5 & -66.0 \\
Fluoride & 32.4 & -56.8 \\
Sulphate & 68.5 & -8.70 \\
Cyanide & 71.2 & -5.10 \\
Chloride & 72.1 & -3.30 \\
Thiosulphate & 73.3 & -2.30 \\
\hline
\end{tabular}

*Data the average of three measurements.

chloride and thiosulphate have comparatively less effect. The serious interference of $\mathrm{PO}_{4}^{-3}$ and $\mathrm{F}^{-}$was due to complex formation with $\mathrm{Ce}$ in aqueous solution. The formation constants of these ions with cerium are higher than with nitrate. These ions act as masking agent for cerium extraction. Therefore, interfering anions must be separated from the aqueous phase prior to extraction.

\subsection{Effect of Cations}

The effect of various cations such as uranium, thorium, zinc, lead, aluminum, and sodium on the extraction of cerium was studied (Table 5). The data indicated that lead, thorium and

Table 5 Various cations effect on Ce extraction (1 M DBSO, $3 \mathrm{M}$ nitric acid, $10.77 \times 10^{-3}$ to $3.56 \times 10^{-3} \mathrm{~mol} \mathrm{dm}^{-3}$ cerium).

\begin{tabular}{ccc}
\hline Cations added/10 $\mathrm{mg} \mathrm{mL}^{-1}$ & Extraction/\% & $\begin{array}{c}\text { Deviation (from } \\
\text { normal value) }\end{array}$ \\
\hline $\mathrm{Nil}$ & 75.0 & $\mathrm{Nil}$ \\
$\mathrm{U}(\mathrm{IV})$ & 65.0 & -13 \\
$\mathrm{Th}(\mathrm{IV})$ & 67.0 & -11 \\
$\mathrm{Zn}(\mathrm{II})$ & 74.0 & -1 \\
$\mathrm{~Pb}(\mathrm{II})$ & 71.0 & -5 \\
$\mathrm{Al}(\mathrm{III})$ & 76.0 & +1 \\
$\mathrm{Na}(\mathrm{I})$ & 73.9 & -1.5 \\
\hline
\end{tabular}

* Data the average of three measurements. 


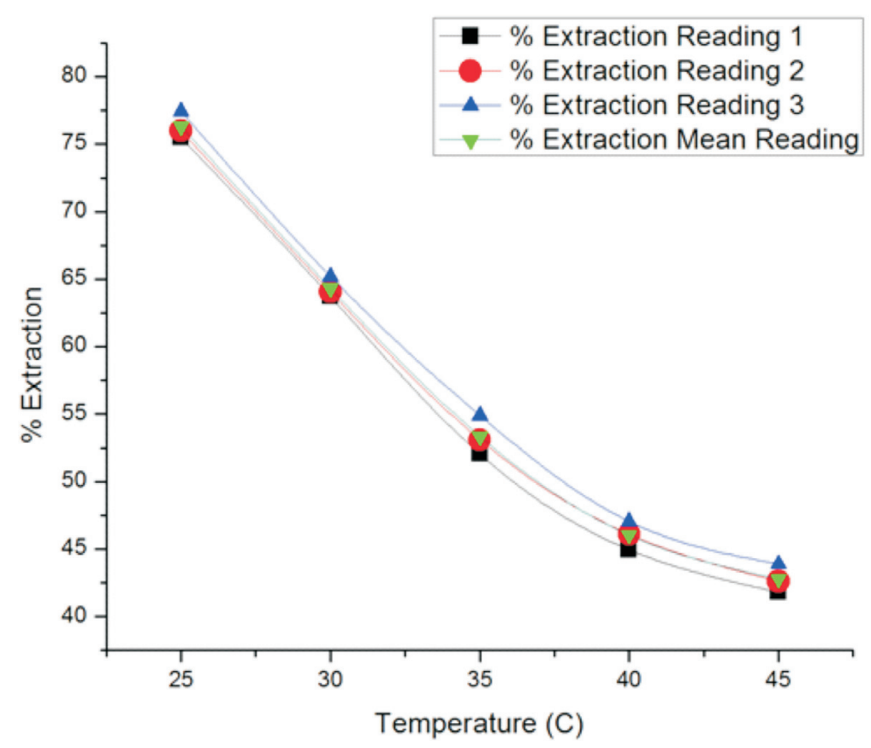

Figure 5 Effect of temperature on the extraction of Ce (1M DBSO, $3 \mathrm{M}$ nitric acid, $10.77 \times 10^{-3}$ to $3.56 \times 10^{-3} \mathrm{~mol} \mathrm{dm}^{-3}$ cerium).

uranium have reduced the normal percentage extraction of cerium while cations such as zinc and sodium have comparatively less effect. An increase in percentage extraction of cerium was noted for $\mathrm{Al}$ (III).

\subsection{Effect of Temperature}

The temperature effect $\left(25\right.$ to $\left.50^{\circ} \mathrm{C}\right)$ on the extraction process was explored. The percentage extraction of Ce (IV) has an inverse relation with increasing temperature. Thus, an increase in temperature does not favour the extraction of cerium because of competition by the other extractable species (Fig. 5). Hence, a lower temperature is favourable for Ce (IV) extraction process used herein.

\subsection{Stoichiometric Composition of the Extracted Complex}

Stoichiometric composition of the cerium DBSO complex was investigated using a slope analysis method (using 3.0 $\mathrm{MHNO}_{3}$ as aqueous phase). Different concentrations of DBSO solution (in chloroform) were used (Figs 6, 7). The following theoretical equation was used to establish the extraction mechanism.

$$
\begin{aligned}
& \mathrm{Ce}^{4+}+4 \mathrm{NO}_{3}^{2-}+\mathrm{nDBSO} \leftrightarrow \mathrm{Ce}\left(\mathrm{NO}_{3}\right)_{4} \cdot \mathrm{nDBSO} \\
& \mathrm{K}_{\mathrm{eq}}=\frac{\left.\mathrm{Ce}\left(\mathrm{NO}_{3}\right)_{4} \cdot \mathrm{nDBSO}\right]_{\mathrm{org}}}{\left[\mathrm{Ce}^{4+}\right]_{\mathrm{aq}}^{2}\left[\mathrm{NO}_{3}^{-}\right]_{\mathrm{aq}}^{4}[\mathrm{DBSO}]_{\mathrm{org}}^{\mathrm{n}}} \\
& \mathrm{As}: \\
& \mathrm{K}_{\mathrm{d}}=\frac{\left.\mathrm{Ce}\left(\mathrm{NO}_{3}\right)_{4} \cdot \mathrm{nDBSO}\right]_{\mathrm{org}}}{\left[\mathrm{Ce}^{4+}\right]^{2}}
\end{aligned}
$$

where $\mathrm{n}$ is the number of DBSO molecules.

$$
\mathrm{K}_{\mathrm{eq}}=\frac{\mathrm{K}_{\mathrm{d}}}{\left[\mathrm{NO}_{3}^{-}\right]_{\mathrm{aq}}^{4}[\mathrm{DBSO}]_{\mathrm{org}}^{\mathrm{n}}}
$$

By taking log on both sides of equation:

$$
\log \mathrm{K}_{\mathrm{eq}}=\log \mathrm{K}_{\mathrm{d}}-\log \left[\mathrm{NO}_{3}^{-}\right]_{\mathrm{aq}}^{4}-\log [\mathrm{DBSO}]_{\mathrm{org}}^{\mathrm{n}}
$$

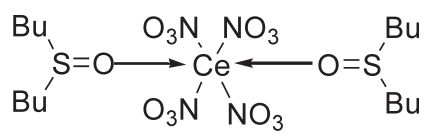

Figure 6 Proposed structure of Ce (IV) complex.

$$
\begin{aligned}
& \text { By rearranging } \\
& \log \mathrm{K}_{\mathrm{d}}=\log \mathrm{K}_{\mathrm{eq}}+4 \log \left[\mathrm{NO}_{3}^{-}\right]+\mathrm{n} \log [\mathrm{DBSO}] \\
& \left.\log \mathrm{K}_{\mathrm{eq}}+4 \log \left[\mathrm{NO}_{3}^{-}\right]=\text {constant }=\mathrm{K}\right] \\
& \log \mathrm{K}_{\mathrm{d}}=\mathrm{K}+\text { nlogDBSO }
\end{aligned}
$$

Equation 5.1 represents a straight line equation giving the slope equal to $n$ and the intercept equal to $\operatorname{logKeq}+4 \log \left(\mathrm{NO}_{3}\right)^{-}$. By using the equation (1), a log-log plot of the distribution ratio versus DBSO concentration at constant concentrations of metal ion and nitric acid and is shown in Fig. 7. Slope (2) suggested that two molecules of DBSO are attached with $\mathrm{Ce}\left(\mathrm{NO}_{3}\right)_{4} .2 \mathrm{DBSO}$.

Cerium preferably coordinates with coordination number 6 or 8 but higher coordination numbers are also possible. ${ }^{44}$ If it is assumed that nitrate ions in this complex are linked to cerium in a mono-dentate mode, then presence of four mono-dentate nitrate groups and the additional two mono-dentate sulfoxide molecules with cerium in the resulting complex give a coordination number of 6 .

\subsection{Stripping of Extracted Cerium}

Aqueous solutions of nitric acid $(0.1 \mathrm{M})$, ammonium hydroxide $(0.1 \mathrm{M})$ and deionized water were used for cerium stripping from the organic phase (DBSO in chloroform, and ammonium hydroxide solution $(0.1 \mathrm{M})$ was found to be the most effective (Table 6). Recovery of cerium with water and $0.1 \mathrm{M} \mathrm{HNO}_{3}$ was found to be $89 \%$ and $75 \%$, respectively. Deionized water was finally chosen as stripping agent based upon the economic consideration and extraction effectivity of cerium from organic phase.

Table 6 Stripping of extracted cerium with different stripants (1M DBSO, $3 \mathrm{M}$ nitric acid, $10.77 \times 10^{-3}$ to $3.56 \times 10^{-3} \mathrm{~mol} \mathrm{dm}^{-3} \mathrm{cerium}_{\text {). }}$

\begin{tabular}{lcccc}
\hline & 1st Stage $/ \%$ & 2nd Stage $/ \%$ & 3rd Stage $/ \%$ & Total recovery $/ \%$ \\
\hline $0.1 \mathrm{M} \mathrm{NH}_{4} \mathrm{OH}$ & 71 & 15 & 3.5 & 89.5 \\
Deionized Water & 68 & 17 & 4.0 & 89.0 \\
$0.1 \mathrm{M} \mathrm{HNO}_{3}$ & 54 & 20 & 1.0 & 75.0 \\
\hline
\end{tabular}

*Data the average of three measurements. 


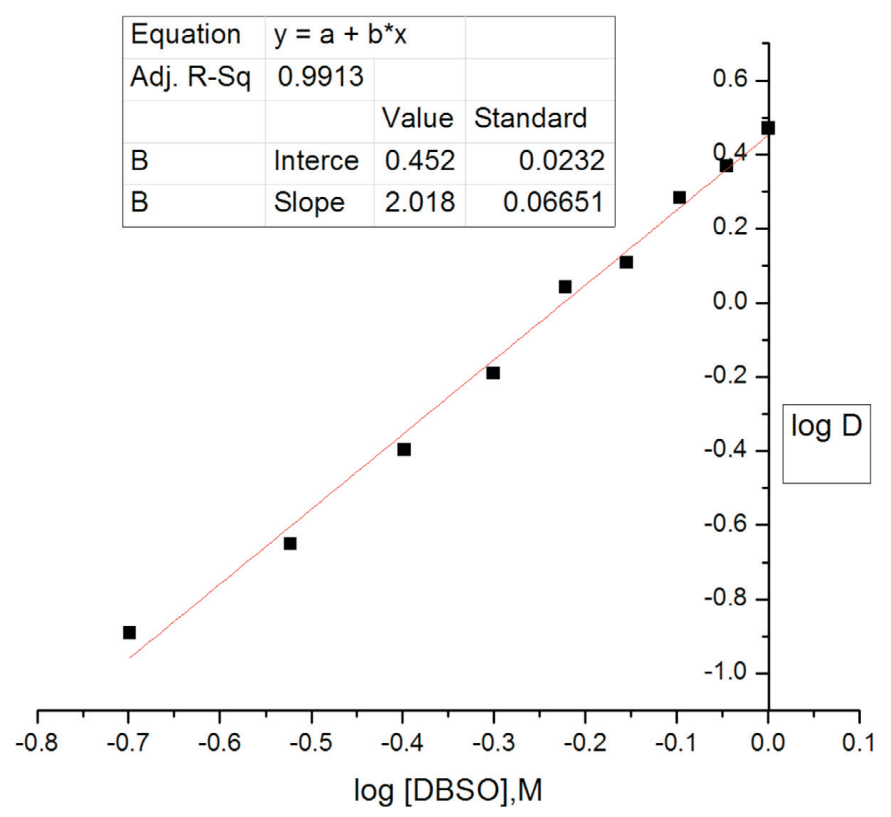

Figure 7 Stoichiometric composition of extracted complex (black square represents the relationship between $\log [\mathrm{DBSO}], \mathrm{M}$ and $\log \mathrm{D}$ while red line represents trend line).

Table 7 Recycling of the extracting agent (1 M DBSO, $3 \mathrm{M}$ nitric acid, $10.77 \times 10^{-3}$ to $3.56 \times 10^{-3} \mathrm{~mol} \mathrm{dm}^{-3}$ cerium).

\begin{tabular}{cc}
\hline No. of cycles & Percentage extraction \\
\hline 1 & 75.0 \\
2 & 74.6 \\
3 & 74.2 \\
4 & 73.0 \\
\hline
\end{tabular}

* Data the average of four measurements.

\subsection{Recycling of the Extracting Agent}

The recycling ability of DBSO (in chloroform) for the extraction of cerium was studied and the process was repeated four times and results are shown in Table 7. Extracting potential of the organic solvent has been checked out and found to be the same after back extraction without any deterioration.

\section{Conclusion}

This method for the cerium extraction is significantly simple, sensitive, selective and reproducible for rapid determination of cerium (IV). Almost quantitative extraction of cerium (IV) from 3.0 M nitric acid solution could be achieved with 1.0 M DBSO solution in chloroform. Higher amount of cerium $(89 \%)$ can be stripped back into the deionized water.

\section{References}

1 D.C. Koskenmaki and K.A. Gschneidner, Handbook on the Physics and Chemistry of Rare Earths, vol. 1, Elsevier B.V. Amsterdam, Netherland, 1978.

2 T. Sahu, S.S. Bisht, K.R. Das and S. Kerkar, Nanoceria, Synthesis and Biomedical Applications, Current Nanoscience, 2013, 9, 1-7

3 J. Hill, Inductively Coupled Plasma Spectroscopy and Its Application, CRC Press, Boca Raton London, U.K., 1999.

4 S. Hirata, T. Kajiva, M. Aihara, K. Honda and O. Shikino, Determination of rare earth elements in seawater by on-line column preconcentration inductively coupled plasma mass spectrometry, Talanta, 2002, 58, $1185-1194$.

5 W. Huang, B. Hu and Z. Jiang, Separation and reconcentration combined with glow discharge atomic emission spectrometry for the determination of rare earth elements ( $\mathrm{La}, \mathrm{Nd}, \mathrm{Eu}, \mathrm{Dy}, \mathrm{Y})$ in Geological Samples, Fresenius J. Anal. Chem., 2000, 366, 36-40.

6 M. Krea and H. Khalaf, Liquid-Liquid Extraction of uranium and lanthanides from phosphoric acid using a synergistic DOPPATOPO mixture, Hydrometallurgy, 2000, 58, 215-225.

7 S. Banerjee and S. Basu, Synergistic extraction of cerium (III) by dipyridyl donor combination, J. Indian Chem. Soc., 2000, 40, 841-848.

8 G. Georgiev and M. Zakharieva, Extraction of lanthanides with mixtures of crown ethers and heptanoic acid, Solvent Extr. Ion Exch., 2001, 21, 735-749.

9 R. Ludwing, D. Lentz and T.K.D. Nguyen, Trivalent lanthanide and actinide extraction by calixarenes with different ring sizes and different molecular flexibility, Radiochim. Acta, 2000, 88, 335-343.

10 J. Zaho, Y. Zuo, D. Li and S. Liu, Extraction and separation of cerium (IV) from nitric acid solutions containing thorium (IV) and rare earths (III) by DEHEHP, J. Alloys Compd, 2004, 374, 438-441.

11 W. Liao, G. Yu, D. Li, Liao, W. Yu, G. and Li, D. 2001. Solvent extraction of cerium (IV) and fluorine(I) from sulphuric acid leaching of bastnasite by cyanex 923, Solvent Extr. Ion Exch., 19, 243-262.

12 B. Gupta, P. Malik and A. Deep, extraction of uranium, thorium and lanthanides using cyanex-923: their separations and recovery from monazite, J. Radioanal. Nucl. Chem., 2002, 251, 451-456.

13 W.P. Liao, G.H. Yu and D.Q. Li, Extraction mechanism of cerium (IV) and fluorine (I) in the separation process of bastnasite leach solution by cyanex 923, Acta Metall Sin., 2001, 14, 21-26.

14 H.D. Revansiddappa and T.N.K. Kumar, Spectrophotometric determination of cerium with leuco xylene cyanol FF, Anal. Sci., 2002, 18, 1275-1278.

15 P.S. Dhami, N.L. Dudwadkar, P.V. Achuthan, U. Jambunathan and P.K. Dey, Radiochemical separation and purification of $144 \mathrm{Ce}$ from Purex high-level waste, Sep. Sci. Technol., 2004, 39, 3143-3150.

16 A.Shimada, T. Yaita, H. Narita, S. Tachimori and K. Okuno, Extraction Studies of lanthanide (III) ions with N, $\mathrm{N}^{\prime}$-dimethyl-N, $\mathrm{N}^{\prime}$-diphenylpyridine-2, 6-dicarboxyamide (DMDPhPDA) from nitric acid solutions, Solvent Extr. Ion Exch., 2004, 22, 147-161.

17 Y.K. Agrawal, S.B. Vora and G. Shah, Solvent extraction, separation and recovery of lanthanum(III) and cerium(IV) from monazite sand by N-phenylbenzo-18-crown-6 hydroxamic acid, Indian J. Chem., 2005, 44, 497-503.

18 Y.Zuo, Y. Liu, J. Chen and D.Q. Li, The separation of cerium (IV) from nitric acid solutions containing thorium (IV) and lanthanides (III) using pure [C8mim] PF6 as extracting phase, Ind. Eng. Chem. Res., 2008, 47, 2349-2355.

19 D.K. Singh, H. Singh and J.N. Mathur, Extraction of rare earths and yttrium with high molecular weight carboxylic acids, Hydrometallurgy, 2006, 81, 174-181.

20 Y.K. Agrawal, Liquid-liquid extraction, separation, preconcentration, and ICP-AES determination of lanthanum and cerium with N-phenyl-(1,2-methanofullerene $\left.C_{60}\right) 61$-formohydroxamic acid, fullerene nanotubes Carbon Nanostruct., 2004, 12, 545-570.

21 L. Jelinek, Y. Wei and M. Kumagaim, Study on separation of Eu(II) from impregnated resin, Solvent Extr. Ion Exch., 2006, 24, 765-779.

22 V.K. Jain, S.G. Pillai and P.H. Kanaiya, Octafunctionalized Calix [4] resorcinarene-N-fenil-acetohydroxamic acid for the separation, preconcentration and transport studies of cerium (IV), J. Braz. Chem. Soc., 2006, 17, 1316-1322

23 S. Abhilash, M.K. Sinha and B.D. Pandey, Extraction of lanthanum and cerium from Indian red mud, Int. J. Miner. Process. 2014, 127, 70-73.

24 N.E. El-Henfy, Y.A. El-Nadi and I.M. Ahmed, 8-Crown-6 for the selective extraction and separation of cerium(IV) from nitrate medium containing some lanthanides, Int. J. Miner. Process., 2011, 101, 58-62.

25 O.S. Helaly, M.S. Abdel-Ghany, M.I. Moustafa, A.H. Abulzaid, N.M. Abdel-Momen and I.M. Ismail, Extraction of cerium(IV) using tributyl phosphate impregnated resin from nitric acid medium, T. Nonfer. Metal. Soc., 2012, 22, 206-214.

26 W. Liao, 26. J. Wang and D. Li, Three phase extraction study of cyanex 923-n-heptane/Ce4+ from $\mathrm{H}_{2} \mathrm{SO}_{4}$ system, Solvent Extr. Ion Exch., 2002, 20, 251-262.

27 W. Liao, G. Yu, S. Yue and D. Li, Kinetics of cerium(IV) extraction from $\mathrm{H}_{2} \mathrm{SO}_{4}-\mathrm{HF}$ medium with cyanex 923, Talanta, 2002, 56, 613-618.

28 F.H. El-Sweify and M.M. Kamel, Studies on the extraction behavior of $\mathrm{Zr}(\mathrm{IV}), \mathrm{Ce}(\mathrm{III}), \mathrm{Th}(\mathrm{IV})$ and U(VI) from aqueous solutions of ArsenazoIII with HDEHP, HTTA, TDA and TCMA, J. Radioanal. Nucl. Chem., 1996, 207, 369-382. 
29 B.N. Kokare, A.M. Mandhare and M.A. Anuse, Liquid-liquid extraction of cerium (IV) from salicylic media using N-7V-octylaniline in xylene as an extractant, J. Chilean Chem. Soc., 2010, 55, 431-435.

30 R.S. Lokhande1, S.P. Janwadkar, P. Shirish, K. Santosh and P. Sanjay, Solvent extraction and spectrophotometric determination of Ce (IV) by using acetophenone 2, 5-dihydroxy semicarbazone as an analytical reagent, Rasayan J. Chem., 2011, 4, 609-612.

31 C.K. Rao, V.K. Reddy and T.S. Reddy, Rapid sensitive spectrophotometric determination of cerium (IV) with 2,4-dihydroxy benzophenone benzoic hydrazone, Talanta, 1994, 4, 237-241.

32 L. Zaijum, Y. Yuling, L. Junkang, P. Jiaomai and Jiantang, Novel sensitive and selective methods for spectrophotometric determination of cerium (III) in biological samples using 2,6-dibromo-4-chlorocarboxyarsenazo, Anal. Lett., 2002, 35, 1959-1963.

33 J. Medina-Escriche, A. Sevillano-Cbeza and M.A.M. Penella, Facile spectrophotometric determination of cerium using malachite greeniodide system in geological and environmental samples, Analyst, 1985, 110, 807-810.

34 S.P. Masti, J. Seetharamappa, M.B. Melwanki and N. Motohashi, Spectrophotometric determination of cerium (IV) using a phenothiazine derivative, Anal. Sci., 2002, 18, 167-172.

35 S. Chandravanshi and V.K. Gupta, Spectrophotometric determination of cerium (IV) in environmental sample, Indian J. Chem., 1978, 16, $548-551$.

36 A.E.N. Desouky, Liquid-liquid extraction of rare earth elements from sulfuric acid solutions, ph.D. thesis, University of Leeds, U.K., 2006.
37 H.C. Mangcsh and V.M. Shinde, Liquid-liquid extraction of cerium in salicylate with tris (2-ethylhexyl) phosphate and tributylphosphine oxide, Solvent Extr. Ion Exch., 2001, 18, 41-54.

38 K.J. Vinod, P.G. Shibu and H.K. Parin, Octafunctionalized calix[4] resorcinaren-e-N-Fenil-acetohydroxamic acid for the separation, preconcentration and transport studies of cerium (IV), J. Braz. Chem. Soc., 2006, 17, 1316-1322.

39 A. Jyothi and G.N. Rao, Solvent extraction behaviour of lanthanum (III), cerium (III), europium (III), thorium (IV) and uranium (VI) with 3-phenyl-4-benzoyl-5-isoxazolone Talanta, 1990, 37, 431-433.

40 D. Zhang, W. Wang, Y. Deng, J. Zhang, H. Zhao and J. Chen, Extraction and recovery of cerium (IV) and fluorine (I) from sulfuric acid solutions using bifunctional ionic liquid extractants, Chem. Eng. J., 2012, $179,19-25$.

41 C. Basulato, F. Valenzuala, L. Molina, J.P. Munoz, E. Fuentes and J. Sapag, Study of the solvent extraction of the lighter lanthanide metal ions by means of organophosphorous extractants, J. Chilean Chem. Soc, 2002, 58, 1785-1789.

42 K.J. Etesh and Y. Pervez, Facile spectrophotometric determination of cerium using malachite green-iodide system in geological and environmental samples, J. Sci. Ind. Res., 2009, 68, 940-944.

43 T.S. Sadallah, K.H. Ghaydaa and A.B. Wadala, Spectrophotometric determination of cerium (III) with arsenazo III: application to sea water and synthetic alloys, Rafidain J. Sci., 2013, 24, 37-50.

44 A.B. Thomas and J. Delgaudio, Crystal structure of ceric ammonium nitrate, Inorg. Chem., 1968, 7, 715-721. 